\title{
Motivational and Educational Value of Game- Based Learning Technology in Law Students Training
}

\author{
Irina N. Chebotareva \\ Department of Criminal Procedure and Forensics \\ Southwest State University \\ Kursk, Russia \\ cheb_irina@mail.ru
}

\author{
Andrey V. Liaskovets \\ Department of Criminal Procedure and Forensics \\ Southwest State University \\ Kursk, Russia \\ skalabor@gmail.com
}

\author{
Olesia S. Pashutina \\ Department of Criminal Procedure and Forensics \\ Southwest State University \\ Kursk, Russia \\ olesya-pashutina@yandex.ru
}

Veronika V. Makhova

Department of Foreign Languages

Southwest State University

Kursk, Russia

veronicamax@bk.ru

\begin{abstract}
The study highlights the motivational force and educational value of game-based learning technology in the educational process. The authors conclude that, on the one hand, games have a great potential for learning because of their dynamism, adaptability and visibility, which provides high sustainable motivation, active user participation and positive learning experience. However, on the other hand, being based on practical approaches and tasks, educational games can contribute to the successful reproduction of knowledge and automation of skills, but do not provide an opportunity to gain a deep and systematic understanding of basic conceptual facts, principles, and theories. In this regard, the authors believe that gaming technology cannot be considered as an alternative to established academic education and does not imply a rejection of traditional forms of transferring information through lectures, textbooks, etc. Only integration of gaming technology in academic education and establishment of a reasonable balance between traditional approaches and this modern technology will allow us to make the process of learning effective and efficient. The article presents an educational game developed by the authors, which will be used in the process of training graduate-students at the Department of Criminal Procedure and Forensics of the Southwest State University (Russia, Kursk).
\end{abstract}

Keywords - educational game; applied games; serious games; higher education; motivation; learning effectiveness

\section{INTRODUCTION}

The Agency for Strategic Initiatives of the Russian Federation identified several main trends for the development of the Russian system of education. The key ones for the issue under consideration are as follows. First, it is the importance of incorporating information and communications technology (ICT) including the Internet into education. Second, it is the modernization of the current education system in Russia, which leads to a change in the educational paradigm. On the one hand, the system provides mass access to affordable education. Teaching and learning process is becoming more personalized due to new technologies, and its content is determined by the needs of each learner, i.e. the way and pace of learning any new material is optimized for each student and even by each student him/herself in such a way that is suitable and effective for him/her. Education based on ICT makes it possible to provide and organize teaching and learning process for millions of people simultaneously. Third, it is introduction of interactive forms of education such as educational entertainment (or edutainment for short) including educational games [1].

It is common knowledge that in Russia, pedagogy in general and legal pedagogy in particular are in crisis: traditional methods and techniques of teaching are not always effective; students, whose intellectual status has changed a lot, are not capable to acquire and absorb new knowledge [2]. Most $21^{\text {st }}$-century students who grew up playing computer games and surfing social networks do not want to listen to lectures and read textbooks, often trusting not their own ideas and ways of thinking, but the RAM of their gadgets and program codes. It can be assumed that if they are not offered new interactive techniques of training and learning, the level of the professional competence of graduates and, as a result, of future practitioners will decrease. So, avoiding the use of the ICT capabilities in the modern world and, consequently, in education is at least unreasonable.

At the same time, educational games in professional education are gaining popularity. Many scientists and practitioners have recognized the enormous potential of educational games due to their dynamic character, adaptivity and visibility applied to a variety of games, which provide high level of motivation, active participation and positive learning experience of a user [3]. Currently, more and more experimental data confirming the effectiveness of educational 
games are being published $[4,5]$. It should be noted that there is no generally accepted definition of the concept used in the works of modern researchers on the topic under study: in some works, we come across 'educational games', 'serious games' [5], others use 'digital game-based learning' or 'applied games' [6]. Despite the lack of general definition and common terminology, the scholars do not mean games for leisure and entertainment, but those the purpose of which is to be used in educational environment in order to provide new knowledge or skills, i.e. to achieve educational goals.

Such forms of edutainment technology as role-plays, case studies, projects, business games, etc. play a special role in teaching professional disciplines in higher educational institutions since they are based on active and collaborative teaching techniques. Moreover, taking into account the fact that modern students spend most of their free time in "virtual world', presented in the form of games through which they can obtain useful knowledge concerning the real world, the use of computer games when including the latter in the academic courses/programs is of particular importance.

This study focuses on two issues: the motivational force and educational value of game-based learning technology in education; assessment is carried out in order to apply the results for creating an educational game that will be used in the process of training postgraduate students at the Department of Criminal Procedure and Forensics of the Southwest State University (Russia, Kursk).

When conducting the research work and writing this article, we used the methods of dialectical materialism (the method of cognizing the phenomena and processes of public life), general scientific methods (observation, analysis, synthesis, comparison, analogy) and particular scientific research techniques (sociological attitude questionnaire).

\section{DISCUSSION}

\section{A. Importance of Games for Improving Students' Motivation}

Games are valued for their motivational force. Play-based activity is the earliest type of cognitive activity of a person. Being familiar to every person from the earliest age, a game develops, encourages, and draws players into its process, contributing to world cognition and understanding. Gamebased learning facilitates perception and knowledge acquisition, increases interest, and stimulates personal development. Motivation is a complex psychological construct related to the energy, intention, and perseverance that actuates person's actions and activities [7]. It is considered as one of the major constituents of effective learning [8]. The results of some studies indicated that as motivation increases, students tend to devote more time answering questions and their accuracy increases [9]. Students' enhanced cognitive activity during the process of learning is the result of sustainable motivation.

Considering gaming motivation, several advantages can be identified:

- A game, affecting person's emotions, makes the process of playing interesting and exciting.
- It reveals creative potential of a person encouraging $\mathrm{him} /$ her to think 'outside the box', enjoying freedom from applying templates and clichés.

- A game contributes to deep involvement of a player into the process encouraging competition and collaboration, the desire to win.

Thus, gaming motivation drives the need for identifying problems and finding solutions to the set challenges and tasks without any coercion, and the gaming process itself provides real enjoyment.

Researchers differentiate between intrinsic and extrinsic motivation. Intrinsic motivation is an inherent tendency of a person to seek out novelty and challenges; to acquire and apply new skills and knowledge; to learn and explore [7]. It is an incentive of a person that drives him/her to participate in an activity caused by the activity itself. On the contrary, extrinsic motivation refers to carrying out an activity being driven by external factors such as external pressure or pursued results, e.g. reward, prestige, diplomas, or salary [3]. Both intrinsic and extrinsic types of motivation are important determining factors affecting students' behaviour. However, extrinsic motives are often known to be less effective than intrinsic ones: extrinsic motives are easily associated with shallow learning rather than deep information processing [10]. A large number of studies showed that intrinsic motivation, compared to extrinsic one, leads to an increased interest, excitation, confidence, and satisfaction, which in turn contributes to increased productivity, perseverance, creativity, self-esteem, overall well-being, surge of vitality [7]. It is the student's intrinsic incentives for cognitive activity and active learning process that play the leading role. Both the process of training highly qualified professionals in general and the effectiveness of the use of gaming technology in particular are directly related to the degree of student's motivation and incentives for acquiring new knowledge, mastering skills and abilities necessary for their future professional activities. Using serious games, it is possible to solve some problems connected with both intrinsic and extrinsic motivation, but it is preferable to develop intrinsic sustainable motivation, that is related to personal inner motives to act, participate in the process of gameplay, and be involved in the context of the game, and not to be aimed only at the results [11]. However, it is commonly known that, in spite of the fact that, as a rule, young people choose the area of their future professional activity themselves, one of the most urgent problems in Russian modern universities is the problem of motivation students to active learning and participating in the educational process. Some of them lose it just at the beginning of their studies, others - either in the middle of the educational course or at its end for various reasons. In this case, application of the means of incentivizing students to productive cognitive activity and active learning process aimed at acquiring new knowledge and obtaining and development of new skills should become the top-priority objective. 


\section{B. Capability of a Game to Train Students}

Most of the game results and achievements are indicators of player's progress, but they do not necessarily indicate student's progress in learning [11].

Unfortunately, in serious games scoring systems are most often to comply with gameplay standards and rules as a whole, not educational standards; as a rule, they are focused on the events of this or that game, and not on the fundamental educational teaching criteria, i.e. skills, knowledge, competence. Therefore, games scoring systems rarely meet the rigorous requirements of validity and reliability of educational learning outcomes.

Striving to strong performance stimulates students to undertake the actions which they have already mastered; they do not want to try anything new because of the fear of getting penalty points. Effective learning requires enough time for deep comprehension, sufficient possibilities for reflection, assessment, reconsideration, and self-evaluation, as well as readiness to make and correct mistakes [3].

It is of paramount importance that game scoring systems should not be based on time criteria and penalty points; they should be focused on learning progress, allowing players to make mistakes and correct them if they can; spend sufficient amount of time and effort; try several attempts; reflect on achievements and make their own strategic decisions. Guided by educational framework in implementation of the scoring system, gaming technology can become much more effective in education. An endeavor to make learning process more attractive should not be carried out at the expense of its effectiveness.

The issue concerning the extent to which educational games are capable to help students acquire new knowledge and skills is also of importance. The undertaken studies provide positive results in relation to this problem [12].

Based on our practical experience, we can also conclude that integration of the game into educational process when you clearly understand its functions contributes greatly to the effectiveness of the former. This can be easily explained due to the fact that firstly, the attractiveness of the game world offered to a student makes the routine activity of remembering, analyzing, revising, and consolidating information obtained in traditional educational forms (lectures, textbooks, etc.) positively emotionally coloured. Another positive aspect of the game is that it contributes to the use of the acquired knowledge in new situations: the acquired material is used in practice in imaginary situations breaking the uniformity of educational process and arousing interest in further cognition of new facts, ideas, etc. So, there is a kind of transfer of knowledge from one situation to another. Educational games in all their diversity facilitate the development of students' abilities to make rational choices when there are multivaried possible decisions to make, decision-making concerning their actions in the conditions of uncertainty and in pseudo-real situation, integration of previously acquired theoretical knowledge and abilities. That, in turn, contributes to the formation of professional skills necessary for their future professional activity. The use of gaming technology also facilitates unconscious self-education, which in its essence is a consequence of using the capabilities of the game world. With the help of large-scale elaborate game situations students can not only learn to apply their doctrinal knowledge obtained from the textbooks, but also, transforming it, get new one which he/she will be able to apply immediately, thereby enlarging the standardized borders of knowledge and education, and expanding his/her horizons. In addition, such a positive feature of educational games as their possibility to form critical attitude to mistakes should be mentioned. When gaming, a student learns from his/her mistakes, having an opportunity to reserve the decision that turned out to be wrong, go back and try other options, make a new decision to determine its advantages and disadvantages and, ultimately, make progress. A student knows that there is nothing wrong in his/her failure: the faster he/she corrects a mistake, the faster a student will be able to find the right solution to the problem.

Educational games reveal the inner potential and abilities of students; contribute to the development and consolidation of certain practical skills and abilities required for further effective professional activities as well as skills and abilities for collecting and analyzing information. They are required for making decisions and actions, independent work, assessing the effectiveness of decisions made, establishing relations between various areas of future professional activity, etc. The use of any form of gaming learning provides wide opportunities for individualization of education, 'erases' the traditional barrier between the teacher and the student.

At present, the use of gaming technology should be recognized as one of the most important elements for training future professionals: it performs cognitive, research, and educational functions

It goes without saying that the model based on experience gained directly from actions performed by a person him/herself often contrasts with the model of traditional education techniques in which mostly passive forms of learning (e.g. learning while reading textbooks or listening to lectures) are involved. Learning through gaming is based on previous and new experience of a person and focuses on actions. Since in educational games practical approaches and tasks are used, they can contribute to successful reproduction of knowledge and lead to automaticy of skills, but do not provide the possibility to gain deep consistent understanding of basic conceptual facts, principles, and theories. Despite the fact that engaging characteristics of educational games as such are valuable, there is a probability that this way of learning will not provide a thorough understanding of consistent patterns and interrelationships of existent content [13]. In the worst-case scenario, a student will undertake an unreflective trial and error strategy which can ultimately lead to the completion of the task without any benefit for his/her learning.

These circumstances suggest the necessity to include educational content into the software of the game.

Thus, the foregoing suggests that gaming technology cannot be considered as an alternative to a well-established academic education and does not imply a rejection of traditional sources of information - lectures, textbooks, etc. 
Only integration of gaming technology and traditional ones as well as establishment of a reasonable balance between the traditional approaches and modern technologies will allow us to build a proper and effective learning process.

\section{USE OF THE RESULTS}

First of all, in order to find out students' attitude towards the use of serious games in the educational process we developed a questionnaire and conducted a questionnaire survey of the students of the Law Faculty of the Southwest State University. The total number of respondents participated in the attitude questionnaire is 115 (aged 20-25). The respondents had an opportunity to opt for several possible answers. On the whole the questionnaire revealed a considerable interest expressed by students to the use of educational games in educational process. Moreover, it indicated a high demand for applying this learning technique among the younger generation. Some results of the survey are shown in Fig. 1. So, 110 students (95.7\% of respondents) consider gamification to be one of the priority techniques for teaching legal courses. At the same time, 57 respondents $(49.6 \%)$ believe that the use of gaming technology increases motivation to study the subject (answer option 1 in Diagram 1 below). 86 students $(76.8 \%)$ are sure that this stimulates interest in the subject (answer option 1). 62 students (53.9\%) indicated the fact that, in their opinion, the use of such technology relieves stress during the educational process (answer option 3). And 29 students (25.2\%) think that educational games contribute to the reduction of the degree of formalism in the educational process (answer option 4); 42 respondents $(36.5 \%)$ indicate that educational games contribute to actualization of knowledge obtained during lecture classes (answer option 5); 57 students (49.6\%) believe that gamification helps to master acquired skills (answer option 6). Most students (67 people) consider the game involving multidisciplinary foundations (Criminal Procedure and Forensic Science; Criminal Procedure, Forensic Science and Criminal Procedural Acts, etc.) to be the most interesting one.

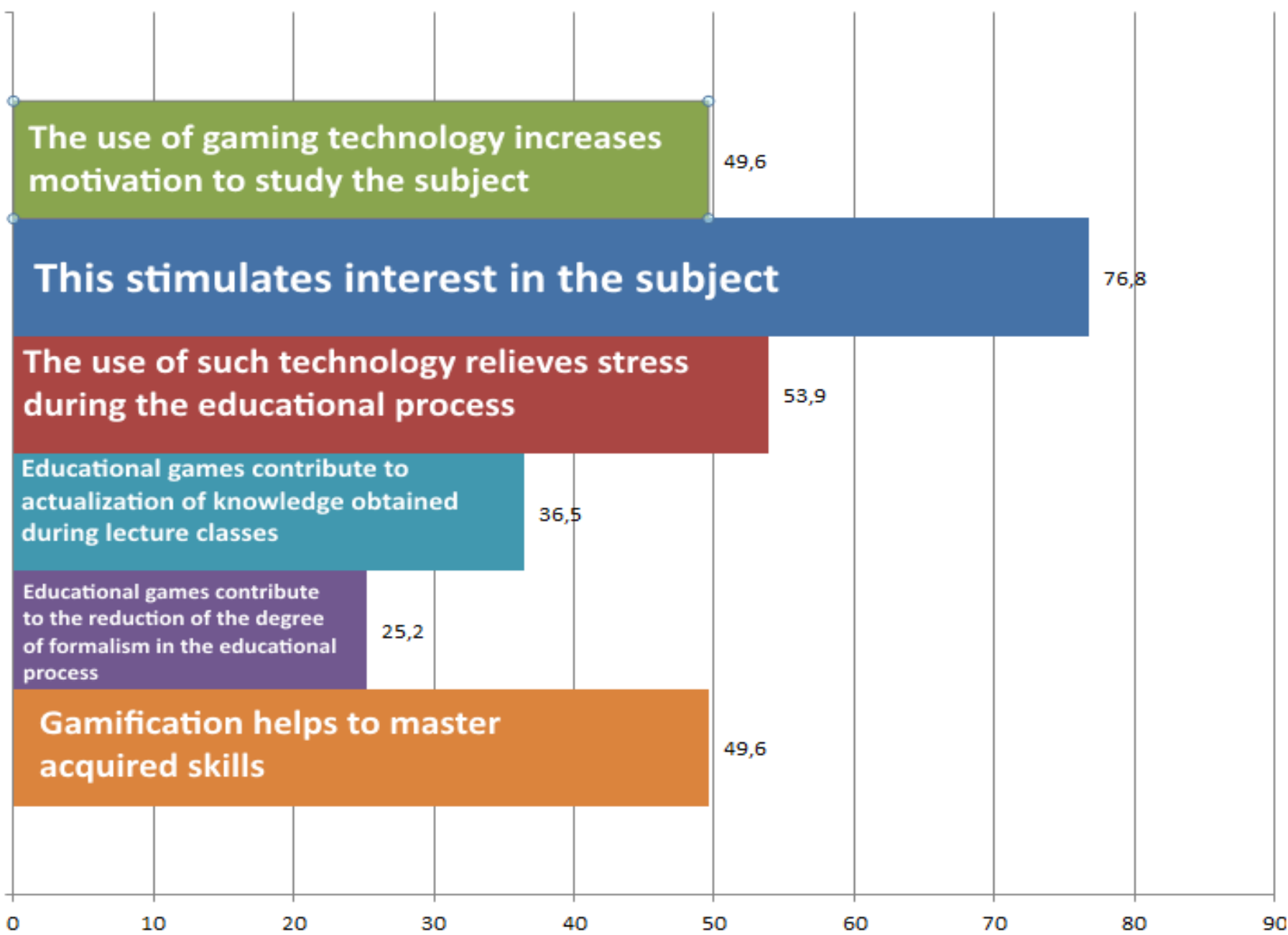

Fig 1. Results of attitude questionnaire survey concerning the use of serious games in the educational process 
The main idea of the proposed educational product, which is being created by our research team, is learning through a serious game. In this case, a game aspect is a kind of incentive to perform certain actions and a motivating trigger for student's activities improvement. At the same time, computer simulation activity, revealing student's inner potential and capabilities, is aimed at mastering those practical skills that will be essential for further studies and everyday effective professional activities. In fact, it is a simulated professional practice for students. To a greater extent, the work of a professional participant in criminal procedure involves mental activity: solving legal problems and making relevant decisions. Hence, in the course of studies at university, students should obtain certain special knowledge, abilities, and skills. In particular, a graduate-student gains knowledge with understanding of theoretical foundations of legal regulation of investigation procedure, trial, and settlement of a criminal case, and the basis of disclosure and investigation of a crime in order to establish objective truth. A graduate-student should be able to choose techniques and methods for preliminary investigation and subsequent trial of a criminal case compliant with the existing legislation of the Russian Federation, to take formal notes of criminal procedure, make decisions and perform legal actions in strict compliance with the law. A graduate-student should be able to implement regulatory provisions of substantive and procedural law, use theoretical knowledge concerning investigation and disclosure of crimes in practice in order to establish objective truth for the case, identify, analyze and find ways to solve problems arising while identifying, preventing, disclosing, and investigating crimes. Therefore, the use of computer games in the quest format - an interactive story with the main character who solves puzzles and tasks that require mental effort - in the educational process will allow students not only to develop professional skills, but also to gain practical experience in resolving legal incidents, and develop critical thinking.

The proposed educational game can be used in the process of mastering almost all subjects which are taught and trained according to Master's Degree Program in Criminal Procedure, Forensic Science, and Theory of Operational Search Activity, since 'criminal case' is a kind of basic concept for all disciplines.

The proposed product is a system of tasks with a developed algorithm of rules, missions and strategies structured logically from the viewpoint of legal regulation of criminal case procedure; the product is designed as a software program aimed at the formation of specific competencies which can be directly transferred into real-life environment.

The setting of the game is the real world, the game plot is a detective story, the main character is an investigator.

The game offers first-person quest gameplay, which concerns finding evidence, interacting with other characters and comparing facts in order to identify the suspect and prove his guilt.

An essential characteristic feature of any detective or crime story as a subgenre of fiction literature is that the actual facts and circumstances of an incident are unknown to the reader, or almost unknown until the investigation is completed. Instead, the author takes the reader through the investigation process described in the book, giving him an opportunity to build his own versions of events and evaluate known facts at each stage of the story. These features allow us to cope with the tasks set: firstly, to simulate future professional activity of the player, and secondly, to focus more on the player's intrinsic motivation.

The computer game developed by our team is based on real events and, therefore, students will use real data to gain the most accurate and realistic experience possible. Playing this game, students will be able, albeit virtually, to bring to life the studied theoretical provisions and principles. The proposed form of gamification creates an image of the real attributes of the activity (e.g., virtual reality technology made it possible to create a three-dimensional image of the incident site). It is a kind of virtual analogue of the real interaction between the participants in the criminal process (game conditions presuppose the implementation of forms of departmental and prosecutorial supervision, and judicial control of the investigator). In addition, it also creates the conditions for substitution of the real performance of professional roles and is an effective form of assessment of the knowledge and skills obtained by the students in professional training.

In order to make a game walkthrough more intriguing, we departed from the plot, which was strictly linear: the game involves changing the storyline depending on the actions of the main character. In addition, taking into account the fact that the success of the quest largely depends on the 'interestingness' of the reaction of the gaming environment to the correct or incorrect actions of the person who acts as an 'investigator', we introduced the characters-prompters into the game: 'a strict teacher' and 'an experienced investigatorcolleague'. They not only play an 'entertaining' role, which consists in a funny reaction to the wrong or inappropriate actions of the main character and leads to emotional release in case of making a mistake but also act as tutors and guides accompanying students into the complex world of legal acts and doctrinal sources. If a student comes to a deadlock, a person will appear on the screen and prompt him which law or recommendations to address to resolve the problem. If a student wants to go to the next level of the game, then he will have to open a textbook or turn to the reference books on legal aspects. In this case, student's independent work with educational, normative and other additional materials will encourage him/her to acquire new skills and knowledge, fill knowledge gaps, and thereby to strive to improve the quality of professional knowledge.

The game uses the following excitements that determine the player's intrinsic motivation:

- The plot, mystery, surprise, unpredictability (to find out how it all ends).

- Discovery, curiosity (to learn something new).

- Anticipation (sensation of revealing a secret).

- Gifts (points).

- Achieved goal (I did it!). 
- Hard-won victory (overcoming obstacles).

- Self-expression (the ability to stand out).

- Limited resources (impatience).

- Collecting.

- Recognition and achievement.

It is expected that being a specific software product with replicated network access, the educational game Interactive Quest "Criminal Case" will provide:

1. The highest degree of implementation of interactive competence-forming methods and techniques when mastering university educational programs, which, in the framework of the introduction of competence approach to the training process that was carried out in Russian higher education system on the turn of the decade, is one of the key foundations indicated in the Federal State Educational Standards and legal regulations of the Ministry of Education and Science of the Russian Federation.

2. Automation and relevant practical focus of university educational programs (including Law Master's Degree programs) on the formation of law-enforcement (professional) and pedagogical (general) competencies provided for the Federal State Educational Standard of Higher Education.

3. A high degree of student involvement and inclusiveness in the learning process due to easy accessibility at any time and any place (where there is access to the Internet), and integration into distance learning system.

4. The increase of rating indicators of the university providing and promoting digital interactive educational technology among the consumers of educational services.

5. The need for scientific analysis of the phenomenon of digital technologies, which will provide sustainable future development, in all areas of jurisprudence and higher education.

\section{CONCLUSION}

The game is an important and necessary means of teaching and learning process, but it should be used in combination with traditional methods and techniques. Certainly, it cannot be considered as an alternative to the established practices of academic education and its use in the educational process does not imply a rejection of traditional forms of information transfer. However, integration of games into educational process, a reasonable balance between traditional approaches and modern gaming technology will allow teachers to build a learning process in which student's inner potential and abilities will be revealed and realized to the fullest extent possible. This process is aimed at mastering by students such a level of practical professional skills that will be sufficient for subsequent effective practical activities.

Game technology is one of the unique forms of learning: it allows teachers to make students' work interesting and exciting not only when performing creative tasks, but also in the course of their everyday routine when studying the basic material.

The use of gaming technology in general, and computer games in particular, when teaching and training future lawyers develops their professional competence and forms the ability to apply theoretical knowledge obtained in the learning process in practical situations. In addition, when they progress through the game in the quest format, students learn to formulate a problem, plan their activities, evaluate alternative opinions, make decisions carefully and independently, and take responsibility for their implementation. Game technology increases students' creative potential, enhances their selfcontrol and self-esteem skills, expands their worldview, and these, together with the foregoing, is a path to a deeper understanding and acquisition of educational material and further success in the formation of relevant competencies of highly qualified professionals of a new generation.

\section{Acknowledgment}

This work was supported by the Vladimir Potanin Foundation; project ID is GK190001698.

\section{References}

[1] P.Luksha, D.Peskov, Global Education Futures: Agenda, iUniverse, 2019.

[2] E.Bayankina, V.Makhova, "Interdisciplinary approach to ELT: a way to meet the challenge", New Times - New Songs: ELT After 2010, pp. 32 34, 2011 [XVII NATE - Russia International Annual Conference, Kaliningrad, 2011].

[3] W.Westera, "Games are motivating, aren't they? Disputing the arguments for digital game-based learning", International Journal of Serious Games, vol. 2, issue 2, pp. 3-17, 2015

[4] E. A.Boyle, T.Hainey, T. M.Connolly, G.Gray, J. Earp, M.Ott, T.Lim, M.Ninaus, C.Ribeiro, J. Pereira, "An update to the systematic literature review of empirical evidence of the impacts and outcomes of computer games and serious games. Computers \& Education”, vol. 94, pp. 178192, 2016.

[5] S.D.Smale, T.Overmans, J.Jeuring, L.V. Grint, "The effect of simulations and games on learning objectives in tertiary education: a systematic review", Proceedings of the GALA 2015, vol. 9599, pp.506516, December 2015 [4th International Conference on Games and Learning Alliance, 2015].

[6] D.Michael, C.Sande, Serious games: games that educate, train, and inform, Boston: Cengage Learning PTR, 2005.

[7] L. van Roessel, J. van Mastrigt-Ide, "Collaboration and team composition in applied game creation processes", Proceedings of the 2011 DiGRA International Conference, vol. 6, pp. 1-14, January, 2011 [DiGRA'11 International Conference: Think Design Play, 2011]

[8] R.M.Ryan, E.L. Deci, "Self-determination theory and the facilitation of intrinsic motivation, social development, and well-being", American Psychologist, vol. 55, issue 1, pp.68-78, 2000.

[9] J.M.Keller, "First principles of motivation to learn and e-learning", Distance Education, vol. 29, issue 2, pp.175-185, 2008

[10] E.Ozcelik, N. E.Cagiltay, N. S. Ozcelik, "The effect of uncertainty on learning in game-like environments", Computers \& Education, vol. 67, pp.12-20, 2013.

[11] M.P.J. Habgood, S.E Ainsworth, "Motivating children to learn effectively: exploring the value of intrinsic integration in educational Games", Journal of the Learning Sciences, vol. 20, issue 2, pp. 169-206, 2011.

[12] W.Westera, "Why and how serious games can become far more effective: accommodating productive learning experiences, learner motivation and the monitoring of learning gains", Educational Technology \& Society, vol. 22, issue 1, pp.113-123, 2019. 
[13] T.M.Connolly, E.A. Boyle, E.MacArthur, T. Hainey, J.M. Boyle, “A systematic literature review of empirical evidence on computer games and serious games", Computers \& Education, vol. 59, issue 2, pp.661686, 2013

[14] R. Mayer, "Should there be a three-strikes rule against pure discovery learning? The case for guided methods of instruction", American Psychologist, vol. 59, issue 1, pp.14-19, 2004.
[15] V.V.Makhova, O.N. Zanina, "Introduction of a new innovative method of foreign language competences formation in the field of professional communication (for the students of nonlinguistic universities)", SGEM: Conference on Psychology \& Psychiatry, Sociology \& Healthcare, Education, pp. 757-764, 2014 [International Multidisciplinary Scientific Conferences on Social Sciences and Arts, 2014]. 